\title{
Efektivitas Pelatihan Kader Posyandu Dalam Penggunaan Buku KIA Dengan Metode Make a Match
}

\author{
Dewi Zolekhah, Elvika Fit Ari Shanti, Liberty Barokah \\ Universitas Jenderal Achmad Yani Yogyakarta \\ Corresponding author: Dewi Zolekhah (dewizolekhah87@gmail.com) \\ Received: December, 16 2019; Accepted: January, 19 2020; Published: March, 152020
}

\begin{abstract}
ABSTRAK
Posyandu berperan dalam pendekatan partisipasi kepada masyarakat di bidang kesehatan. Posyandu dikelola oleh kader. Tugas kader posyandu dalam kegiatan KIA salah satunya adalah melakukan pencatatan. Kenyataanya masih banyak kader posyandu yang tidak mengetahui cara menggunakan buku KIA. Selama ini kader telah memperoleh pelatihan dan penyegaran tentang Buku KIA. Pendekatan yang digunakan dalam pelatihan tersebut adalah konvensional, yaitu pelatihan diberikan secara ceramah dan tanya jawab. Kelemahan dari metode ini yaitu pengetahuan yang didapatkan cepat terlupakan. Metode Make A Match merupakan salah satu jenis dari metode dalam pembelajaran kooperatif. Keunggulannys adalah cara peserta belajar mengenai suatu topik/konsep dengan membuat kartu soal dan jawaban dan mencocokan kartu tersebut serta mengikuti pembelajaran dengan aktif dan suasana yang menyenangkan. Penelitian ini bertujuan untuk mengetahui efektivitas pelatihan kader posyandu dalam penggunaan buku KIA dengan metode make a match di Desa Lumbungrejo. Jenis penelitian ini adalah pra eksperimental, dengan rancangan penelitian one group pre test-post test group design. Populasi dalam penelitian ini yaitu seluruh kader posyandu yang terdapat di Desa Lumbungrejo sebanyak 30 orang. Teknik sampel dengan total sampling. Analisis data menggunakan Wilxocon Sign test, didapatkan $\mathrm{p}$ value $(0,000)<0,005$ sehingga terdapat perbedaan yang bermakna terkait pengetahuan kader sebelum dan sesudah diberikan pelatihan tentang penggunaan Buku KIA Dengan Metode Make A Match.
\end{abstract}

Kata Kunci: Pelatihan, Kader, Buku KIA

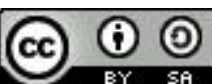

This is an open-acces article distributed under the terms of the Creative Commons Attribution-ShareAlike 4.0 International License.

\section{PENDAHULUAN}

Posyandu merupakan salah satu bentuk Upaya Kesehatan Bersumber Daya Masyarakat (UKBM) yang dikelola dan diselenggarakan dari, oleh, untuk dan bersama masyarakat dalam penyelenggaraan pembangunan kesehatan, guna memberdayakan masyarakat dan memberikan kemudahan kepada masyarakat dalam memperoleh pelayanan kesehatan (Kemenkes, 2011).

Posyandu dikelola oleh kader yang telah memperoleh pelatihan salah satunya dari bidan Puskesmas (Kemenkes, 2011). Kader adalah warga masyarakat setempat yang dipilih dan ditinjau oleh masyarakat dan dapat bekerja secara sukarela mengelola posyandu. Tugas kader 
posyandu dalam kegiatan KIA adalah melakukan pen-daftaran, penimbangan, mencatat pelayanan ibu dan anak dalam buku KIA, menggunakan buku KIA sebagai bahan penyuluhan dan melaporkan penggunaan buku KIA kepada petugas kesehatan (Kemenkes, 2011). Kader posyandu merupakan health provider yang berada di dekat kegiatan sasaran posyandu, Intensitas pertemuan kader lebih sering daripada petugas kesehatan lainnnya. Tugas kader posyandu dalam kegiatan KIA yaitu melaksanakan tugas di bagian pendaftaran, penimbangan, mencatat pelayanan ibu dan anak dalam buku KIA, menggunakan buku KIA sebagai bahan penyuluhan dan melaporkan penggunaan buku KIA kepada petugas kesehatan (Kemenkes, 2011). Buku KIA merupakan alat untuk mendeteksi secara dini adanya gangguan atau masalah kesehatan ibu dan anak, alat komunikasi dan penyuluhan dengan informasi yang penting bagi ibu, keluarga, dan masyarakat mengenai pelayanan kesehatan ibu dan anak termasuk rujukannya dan paket (standar) pelayanan KIA, gizi, imunisasi, dan tumbuh kembang balita (Kemenkes, 2011).

Sistiarini, dkk (2013) menyebutkan bahwa pengetahuan berhubungan dengan peran kader dalam penggunaan buku KIA. Penelitian lain menunjukan bahwa pengetahauan kader tentang KMS baru $68,75 \%$ berpengetahuan kurang. Pengetahuan yang kurang dipengaruhi oleh seberapa lama menjadi kader dan faktor rendahnya status pelatihan yang dimiliki oleh kader di Posyandu. Pengetahuan kader baru $25 \%$ berpengetahuan cukup, hal ini disebabkan karena faktor status pelatihan dan seberapa lama menjadi kader. Seperti dijelaskan oleh Ainiyah bahwa kurangnya pengetahuan tentang penggunaan buku KIA menjadi kendala dalam pembentukan perilaku kesehatan ibu hamil tentang pentingya melakukan periksa kehamilan secara rutin (Ainiyah, 2017).

Menurut Tanjung (2003) yang dikutip dari Pratiwi (2012), pelatihan merupakan suatu proses belajar mengajar terhadap pengetahuan dan keterampilan tertentu serta sikap agar semakin terampil dan mampu melaksanakan tanggung jawabnya dengan semakin baik, sesuai dengan standar. Pelatihanberarti mengubah pola perilaku, karena dengan pelatihan maka akhirnya akan menimbulkan perubahan perilaku. Pelatihan adalah bagian dari pendidikan yang menyangkut proses belajar, berguna untuk memperoleh dan meningkatkan keterampilan di luar system pendidikan yang berlaku, dalam waktu relative singkat dan metodenya mengutamakan praktek daripada teori. Kemenkes (2011) menyatakan bahwa tujuan pelatihan adalah suatu usaha untuk meningkatkan sumberdaya manusia termasuk tenaga kesehatan, kader posyandu, agar pengetahuan dan keterampilannya meningkat. Kader posyandu perlu mendapatkan pelatihan karena jumlahnya tersebar di berbagai daerah di Indonesia. Pelatihan perlu didesain secara efektif untuk memastikan bahwa program pelatihan telah mencapai efisiensi yang optimal serta mencapai keuntungan belajar yang maksimum.

Berdasarkan hasil studi pendahuluan yang dilakukan pada 15 kader di Desa Mororejo, Tempel, Sleman, Yogyakarta didapatkan bahwa 8 kader mengatakan belum mengetahui bagaimana penggunaan buku KIA yang benar dan 7 kader mengatakan kurang paham apabila mendapatkan penyegaran disebabkan metode yang digunakan adalah metode konvensional yaitu ceramah dan tanya jawab sehingga kader merasa bosan. Melihat betapa pentingnya peran kader dalam penggunaan buku KIA maka perlu diadakan training/pelatihan pada kader posyandu tentang penggunaan buku KIA dengan metode make a match. Model pembelajaran make and match adalah sistem pembelajaran yang mengutamakan penanaman kemampuan sosial terutama kemampuan bekerja sama, kemampuan berinteraksi di samping kemampuan berpikir cepat melalui permainan mencari pasangan dengan dibantu kartu (Huda, 2011). Metode make a match pernah diteliti dengan nama metode find your mate. Subyek penelitian 
yang dilakukan Rufiati pada metode find your mate yaitu kader dengan hasil penelitian yaitu metode find your dapat meningkatkan pengetahuan (Rufianti dkk, 2011).

Selain itu metode pembelajaran kooperatif ini juga pernah diteliti dengan nama index card match dan hasilnya metode index card match dapat meningkatkan pengetahuan kader (Susanti, 2016). Keberhasilan kegiatan posyandu sangat bergantung pada partisipasi secara aktif dari kader yang bertugas di posyandu dengan sukarela mengelola posyandu di wilayahnya masing - masing. Kurangnya pelatihan dan pembinaan untuk meningkatkan keterampilan yang memadai bagi kader menyebabkan kurangnya pemahaman terhadap tugas kader, lemahnya informasi serta kurangnya koordinasi antara petugas puskesmas dengan kader dalam pelaksananan kegiatan posyandu sebagai penyelenggaran pelayanan profesional untuk membimbing kader agar mampu memberikan pelayanan kesehatan kepada masyarakat secara optimal (Kemenkes, 2011).

\section{METODE}

Jenis penelitian yang digunakan adalah penelitian pra exsperimental dengan rancangan penelitian one group pretest postes design. Populasi dalam penelitian iniadalah seluruh kader posyandu Posyandu di Desa Mororejo, Tempel, Sleman, Yogyakarta Sebanyak 30 kader yang memenuhi kriteria inklusi dan tidak memiliki kriteria eksklusi menjadi sampel dalam penelitian ini dan diambil secara total sampling. Pengumpulan data dilakukan dengan menggunakan lembar kuesioner sebelum dan sesudah diberikan pelatihan dengan metode make a match. Analisis data dilakukan menggunakan uji paired sample t- test untuk melihat perbedaan.

HASIL PENELITIAN

Karakteristik Penelitian

Tabel 4.1. Distribusi Frekuensi Karakteristik Responden

\begin{tabular}{clcc}
\hline No & Variabel & Frekuensi & Persentase (\%) \\
\hline 1. & Umur & 0 & 0 \\
& $<20$ Tahun & 15 & 46,7 \\
& 20-35 Tahun & 16 & 53,3 \\
& $>35$ Tahun & & \\
\hline 2. & Pendidikan & 4 & 13,33 \\
& SMP & 24 & 80 \\
& SMA & 2 & 6,67 \\
& D-3 & & \\
3. & Pekerjaan & 25 & 83,33 \\
& IRT & 2 & 6,67 \\
& Petani & 3 & 10 \\
& Swasta &
\end{tabular}

Sumber : Data Primer, 2018

Berdasarkan tabel 4.1, dapat diketahui bahwa karakteristik responden berdasarkan umur sebagian besar adalah usia $>35$ tahun sebesar 53,3\%. Karaketeristik responden berdasarkan pendidikan sebagian besar adalah SMA sebesar $80 \%$ dan karakteristik responden berdasarkan pekerjaan sebagian besar adalah IRT $83,33 \%$. 
Pengetahuan Kader Posyandu Sebelum Dan Sesudah Diberikan Pelatihan Tentang Penggunaan Buku Kia Dengan Metode Make A Match

Tabel 4.2. Pengetahuan kader Posyandu sebelum di berikan pelatihan tentang penggunaan Buku KIA Dengan Metode Make A Match

\begin{tabular}{ccccc}
\hline & \multicolumn{2}{c}{ Sebelum Pelatihan } & \multicolumn{2}{c}{ Sesudah Pelatihan } \\
\cline { 2 - 5 } Kategori & Frekuensi & \% & Frekuensi & \% \\
\cline { 2 - 5 } Baik & 1 & 3,3 & 20 & 66,7 \\
Cukup & 9 & 30 & 10 & 33,3 \\
Kurang & 20 & 66,7 & 0 & 0 \\
Jumlah & 30 & 100 & 30 & 100 \\
\hline
\end{tabular}

Sumber : Data Primer, 2018

Berdasarkan tabel 4.2, dapat diketahui bahwa tingkat pengetahuan kader sebelum diberikan pelatihan dalam kategori baik 1 orang $(3,3 \%)$ setelah diberikan pelatihan meningkat menjadi 20 orang $(66,7 \%)$.

\section{Perbedaan Tingkat Pengetahuan Sebelum Dan Sesudah Diberikan Pelatihan Tentang Penggunaan Buku Kia Dengan Metode Make A Match}

Uji normalitas pada penelitian ini menggunakan uji statistik Saphiro-Wilk, dimana jika nilai $\mathrm{p}$ $>\alpha(0,05)$, maka secara statistik data tidak berdistribusi normal. Sedangkan, jika nilai $\mathrm{p}<\alpha$ $(0,05)$, maka secara statistik data berdistribusi normal. Uji beda pada penelitian ini menggunakan uji Wilcoxon karena data tidak berdistribusi normal.

Tabel 4.4 Hasil uji Normalitas Data Tingkat Pengetahuan

\begin{tabular}{ccccc}
\hline Variabel & kelompok & N & p-value & $\begin{array}{c}\text { Kesimpul } \\
\text { an }\end{array}$ \\
\hline Pengetahuan & Pre test & 30 & 0,025 & Tidak \\
& Post Test & 30 & 0,065 & $\begin{array}{c}\text { Normal } \\
\text { Normal }\end{array}$
\end{tabular}

Keterangan: Jika $p$-value $<0.05$ berarti tidak berdistribusi normal $p$-value $>=0.05$ berarti data terdistribusi normal

Pada tabel 4.6 berdasarkan hasil wilcoxon menunjukkan bahwa ada perbedaan yang bermakna $(\mathrm{p}=0.000<\propto)$ pengetahuan kader sebelum dan sesudah diberikan pelatihan tentang penggunaan Buku KIA Dengan Metode Make A Match

\section{PEMBAHASAN}

Metode Make a Match merupakan salah satu tipe dalam model pembelajaran kooperatif. Metode ini digunakan dalam penelitian terhadap kader dengan cara mengajak peserta dalam kegiatan ini yaitu kader posyandu untuk berperan aktif dalam proses pembelajaran dengan cara mencari kartu jawaban dan pertanyaan, sehingga dapat menciptakan proses pembelajaran yang menyenangkan sehingga materi yang disampaikan mudah di terima dan dilaksanakan (Huda, 2011). Menurut teori, alat bantu berfungsi untuk membantu proses pembelajaran yang disusun berdasarkan pengetahuan manusia kemudian diterima melalui panca indera sehingga semakin banyak indera yang digunakan dalam menerima pesan, maka semakin banyak pengetahuan yang didapatkan (Notoadmodjo, 2012). 
Cara belajar dalam metode make a match berbeda dengan cara belajar dalam pembelajaran konvensional yang berupa ceramah dan tanya jawab. Dalam metode ceramah peserta terlalu pasif yaitu hanya mendengarkan materi dan ini akan membuat pengetahuan yang diperoleh cepat terlupakan, karena dengan mendengar ingatan yang diperoleh akan lebih sedikit dibandingkan dengan mendengar, melihat, diskusi, dan melakukan (Huda, 2013).

Metode yang bisa diterapkan salah satunya dengan metode pembelajaran yang koperatif dan aktif dari peserta salah satunya yaitu dengan metode make a match yang merupakan metode pembelajaran dengan cara peserta belajar mengenai suatu topik/konsep dengan membuat kartu soal dan jawaban dan mencocokan kartu tersebut serta mengikuti pembelajaran dengan asyik, sehingga dapat meningkatkan keaktifan peserta dan proses belajar menyenangkan sekaligus melatih keberanian peserta dalam mempresentasikan hasil jawaban sehingga hasil pembelajaran dapat maksimal (Sibelman, 2013; Suprijono, 2013: Huda, 2013). Metode make a match terbukti dapat meningkatkan pengetahuan dan keterampilan peserta. Metode make a match dapat memaksimalkan aktivitas peserta untuk memperoleh informasi. Informasi yang didapat kemudian akan disampaikan kepada peserta yang lain agar semua peserta mengetahui informasi yang didapat dari setiap pasangan, selain itu dengan menggunakan metode make a match ini dapat diketahui tingkat penguasaan peserta terhadap materi yang dipelajari (Rufianti, 2011; Suprijono, 2013; Hamruni, 2012). Menurut Dale dari klasifikasi 11 tingkatan pengalaman belajar yaitu kata, tulisan, radio, film, televisi, pameran, field trip, demonstrasi, sandiwara, benda tiruan, dan benda asli. Bermain sandiwara (simulasi) mempunyai intensitas yang lebih baik, yaitu pada tingkat 9 dibandingkan penyampaian bahan dengan kata-kata dan tulisan yang mempunyai intensitas paling rendah dalam hal mempersepsikan bahan pendidikan atau pengajaran (Notoadmodjo, 2012; Aqip, 2013). Simulasi adalah kegiatan pembelajaran yang memberi kesematan kepada pembelajaran untuk meniru satu kegiatan yang dituntut dalam pekerjaan sehari-hari atau yang berkaitan dengan tanggung jawabnya.

Berdasarkan tabel 4.2, dapat diketahui bahwa tingkat pengetahuan kader sebelum diberikan pelatihan dalam kategori baik 1 orang $(3,3 \%)$ setelah diberikan pelatihan menggunakan metode make a match meningkat menjadi 20 orang $(66,7 \%)$. Pada tabel 4.6 berdasarkan hasil wilcoxon menunjukkan bahwa ada perbedaan yang bermakna $(p=0.000<\propto)$ pengetahuan kader sebelum dan sesudah diberikan pelatihan tentang penggunaan Buku KIA Dengan Metode Make A Match Hasil penelitian ini sesuai dengan teori yang menyatakan bahwa pendidikan kesehatan merupakan upaya untuk meningkatkan pengetahuan kader posyandu sehingga kader bisa memberikan informasi yang jelas dan benar pada ibu hamil yang datang ke posyandu (Notoadmodjo, 2012). Pengetahuan yang dimiliki juga merupakan salah satu faktor yang menentukan untuk menuju dan memanfaatkan fasilitas kesehatan yang bersifat preventif dan promotif, dalam hal ini kegiatan pendidikan kesehatan. Pengetahuan yang lebih baik tentang manfaat serta akibat atau dampak yang ditimbulkan oleh suatu tindakan akan menyebabkan individu mengalami perubahan perilaku dengan berusaha mencari upaya pencegahan dan dampak (Notoadmodjo, 2012).

Pengetahuan dapat diartikan tahu atau mengerti sesudah melihat (menyaksikan, mengalami atau diajar). Kader yang memiliki pengetahuan yang baik diharapakan akan dapat memberikan layanan yang baik dan bermutu pada saat Posyandu. Pengetahuan dapat diartikan tahu atau mengerti sesudah melihat (menyaksikan, mengalami atau diajar). Pengetahuan kader dapat meningkat seiring dengan lama manjadi kader, pengalaman di lapangan dalam menangani kasus dan pelatihan-pelatihan yang telah diikuti. Dengan pengetahuan yang bertambah diharapakan dapat memberikan pelayanan yang lebih baik kepada masyarakat (Widagdo, 2009).

Peningkatan pengetahuan tentang penggunaan buku KIA ini tidak terlepas dari peran pelatihan yang telah diberikan dengan metode make a match yang menyebabbkan kader 
mudah menyerap informasi yang diberikan terkait penggunaan buku KIA yang baik dan benar sehingga kader akan berusaha untuk menggunakan dan memanfaatkan buku KIA dengan baik dan menginformasikan semua informasi yang ada di buku KIA kepada ibu hamil dan ibu yang mempunyai bayi balita yang datang ke posyandu. Hal tersebut sesuai dengan teori yang menyatakan bahwa faktor penting yang membentuk tindakan seseorang adalah pengetahuan yang diperoleh (Notoadmodjo, 2012).

\section{KESIMPULAN}

Pelatihan dengan menggunakan metode make a match efektif dalam meningkatkan pengetahuan kader dalam menggunakan buku KIA dengan $p$ value $<0,05$.

\section{DAFTAR PUSTAKA}

Kementerian Kesehatan RI. Pedoman Umum Pengelolaan Posyandu. Jakarta. 2011

Kementrian Kesehatan RI. Buku Panduan Kader Posyandu Menuju Keluarga Sadar Gizi. Bakti Husada: Jakarta. 2011

Pratiwi,N . Pengaruh Pelatihan Gizi Seimbang Terhadap Peningkatan Pengetahuan dan Keterampilan Kader Posyandu Lansia. Skripsi Fakultas Kesehatan Masyarakat Universitas Indonesia. Jakarta. 2011

Huda M. Cooperative learning. Metode, Teknik, Struktur, dan Model Penerapan. Yogyakarta: Pustaka Belajar. 2011

Rufianti AM, Raharjo B, Indrawati F. 2011. Pengaruh Metode Permainan Find Your Made Terhadap Peningkatan Pengetahuan Kader Posyandu. Jurnal Kesehatan Masyarakat. 2011;2:113-9.

Sistiarani C, Nurhayati S, Suratman. 2013. Faktor Yang Mempengaruhi Peran Kader Dalam Penggunaan Buku Kesehatan Ibu Dan Anak. Jurnal Kesehatan Masyarakat. 2013. 2 : $77-84$

Ainiyah, Nur Hidayatul., Mohamad Hakimi, Anjarwati, Hubungan Pemanfaatan Buku Kesehatan Ibu Dan Anak (KIA) Dengan Tingkat Pengetahuan Dan Perilaku Kesehatan Ibu Hamil Trimester III Di Puskesmas Jagir Surabaya. 2017. http://digilib.unisayogya.ac.id

Kementrian Kesehatan RI. Buku Kesehatan Ibu dan Anak. Jakrta: Bakti Husada. 2011

Susanti. 2016. Efektifitas Pelatihan Kader Posyandu Tentang Deteksi Dini Tanda Bahaya Kehamilan Dengan Metode Indeks Card Match. Jurnal Kesehatan Al-Irsyad. 2016; 9 (2)

Notoadmodjo S. Promosi Kesehatan dan Perilaku Kesehatan. Rineka Cipta: Jakarta; 2012

Widagdo, 2009. pemanfaatan buku KIA oleh kader posyandu: studi pada kader posyandu di wilayah kerja puskesmas kedungadem kabupaten bojonegoro. Jurnal Makara. 2009; 13 (1)

Yuniar. Pengaruh Heath Promotion Model Terhadap Peningkatan Pengetahuan Dan Motovasi Kader Posyandu. Skripsi Fakultas Kedokteran dan Ilmu Kesehatan Universitas Jenderal Soedirman. Purwokerto. 2012

Laraeni. 2014. Pengaruh penyegaran kader terhadap pengetahuan dan keterampilan kader posyandu mneggunakan dacin di wilayah kerja Puskesmas dasar cermen kecamatan Sandubaya Kota mataram. Media Bina Ilmiah. 2014; 8 Volume (4)

Sibelman M. Active Learning 101 Cara Belajar Siswa Aktif. Revisi ed. Nusa Media \& Nuansa Cendikia. Bandung.2013

Suprijono A, 2013. Cooperative Learning Teori dan Aplikasi PAIKE. Pusaka Pelajar. Yogyakarta. 2013 